\title{
Factors affecting the performance of foreign direct investment in the renewable energy supply chain
}

\author{
Pham Thu Phuonga ${ }^{a^{*}}$, Nguyen Duc Duong ${ }^{\mathrm{b}}$ and Nguyen Thi Thu Ha ${ }^{\mathrm{b}}$
}

${ }^{a} V N U$ University of Economics \& Business, Vietnam

${ }^{b}$ Hanoi University National Resources and Environment, Hanoi, Vietnam

\section{H R O N I C L E}

\section{Article history:}

Received September 18, 2020

Received in revised format May 8 , 2021

Accepted August 282021

Available online

September 12021

Keywords:

Business Performance

Foreign Direct Investment

Renewable Energy Supply Chain

\section{A B S T R A C T}

The development of Vietnam's economy in recent years has had positive contributions from the foreign direct investment (FDI) sector to the realization of socio-economic goals. The study found four factors affecting the business performance of FDI enterprises in the renewable energy supply chain: internal environment, user pressure, cooperation with suppliers, and environmental regulations. Synthesized research from 395 survey questionnaires at renewable energy enterprises in Vietnam. High-tech, low-energy businesses and the environmental goods sector can benefit Vietnam's environment and help the country achieve its green growth goals.

(C) 2022 Growing Science Ltd. All rights reserved.

\section{Introduction}

The growth of renewable energy sources is unavoidable ( $\mathrm{Li}$ et al., 2016). One of their important tools for realizing the renewable energy economy is to promote communication in the direction of the new driving force of the renewable energy economy, which is environmental protection, the development of clean production technology, and clean energy to achieve rapid and sustainable economic growth (Dincer, 2000; Viardot, 2013). Consider the United States, which is one of the leading countries in terms of renewable energy economic policy. They have adopted new policies to help the economy recover, such as energy development, renewable energy economic development, energy conservation policies, pollution reduction, and renewable energy policies to create energy (Painuly, 2001; Worighi et al., 2019). They support propaganda efforts to execute the energy conservation policy, with the objective of renewable energy sources accounting for around $25 \%$ of power output by 2025 . Similarly, the European Union has set a goal of increasing renewable energy consumption from 8.5 percent to 20 percent by 2020, while substantially reducing emissions. Many Asian countries have likewise established an economic growth plan based on renewable energy. Korea is predicted to become one of the world's seven renewable energy economic powerhouses by 2020, and one of the world's five by 2050 (Bhattacharya et al., 2016; Kumar et al., 2010; Dai et al., 2016).

Vietnam has a lot of potential when it comes to utilizing renewable energy sources including hydropower, wind power, solar power, and biomass power (Tien et al., 2020; Hoi, 2020). In Vietnam, hydroelectricity is being developed to its full potential. By the end of 2018, hydropower has become our country's primary energy source, accounting for more than $40 \%$ of total national electrical capacity. Hydro and other types of renewable energy (including small hydropower) account for 2.1 percent of the overall capacity of the system, excluding medium and big hydropower. However, nothing remains constant. before the passage of time. Thanks to the FIT price support mechanism, more over 80 solar power facilities have been operational and closed as of mid-2019, whereas just two small-scale solar power plants were linked to the electricity grid at the end of 2018. The entire solar power capacity at the time was over $4460 \mathrm{MW}$, accounting for more than $8 \%$ of the system's overall producing

* Corresponding author

E-mail address: ptphuong86868@gmail.com (P. T. Phuong)

(C) 2022 Growing Science Ltd. All rights reserved.

doi: $10.5267 /$ j.uscm.2021.9.002 
capacity. Meanwhile, Vietnam's total wind power capacity was just 228 MW at the end of 2018, but by 2019, the number of wind power projects under development with a total capacity of 2,000 MW would be more than double that of the previous year. Commercial power generation from biomass energy is still progressing slowly due to the challenge of bagasse price support. However, considering the growing volume of municipal and agricultural waste, forestry products, and the government's work on the Renewable Portfolio Standard, the prospects for this energy source's expansion remain optimistic (Cuong et al., 2021; Tran, 2018).

\section{Literature review}

\subsection{Foreign direct investment in renewable energy}

In 2015 , renewable energy accounted for 19.3 percent of total global energy consumption. Renewable energy is quickly growing in popularity throughout the world, and the trend is becoming increasingly apparent. Renewable energy production is no longer limited to a few small nations; it is now a worldwide phenomenon.

Over the last 30 years, Vietnam's economy has shifted from an energy-intensive agricultural economy dependent on traditional biomass fuels to an industrial economy focused on modern and synthetic forms of energy. In 2015, Vietnam's total primary energy supply was 70.6 million tons of oil equivalent (TOE), with commercial energy accounting for 81.1 percent of total primary energy consumption and non-commercial energy accounting for $16.9 \%$. Hydroelectricity has become an essential major source of energy for electricity production in recent years, with capacity and electricity produced by hydroelectric facilities accounting for a significant percentage of Vietnam's power production structure. Vietnam will prioritize the development of renewable energy sources for electricity generation, with the goal of increasing the share of electricity generated from renewable energy sources (excluding big and medium-sized hydropower) to $7 \%$ by 2020 and above $10 \%$ by 2030 (Michael Braun, 2018).

Traditional energy sources are steadily diminishing owing to limited supplies and rising demand, according to the Vietnam Energy Association. As a result, boosting renewable energy investment is one of the best options. Vietnam's ability to attract investment money will improve in the future. Encouraging foreign direct investment (FDI) in the fields of clean energy, high technology, energy efficiency, and environmental goods may assist Vietnam's environment and help the nation realize its green growth goals.

\subsection{Hypothesis}

According to Zhu and Sarkis (2006), supply chain management encompasses everything from green purchasing to an integrated supply chain that runs from supplier to manufacturer to consumer and back, forming a complete loop. These positions necessitate the development of connections between partners in the execution of green initiatives, which may include direct participation of suppliers and customers in the adoption of new manufacturing methods or product modifications (Chavez et al., 2016).

In the renewable energy sector, successfully integrating sustainability into the supply chain necessitates the development of a consistent policy and management structure, as well as the establishment of defined goals and actions for economic, environmental, and social efficiency (Baumgartner \& Rauter, 2017). The development of this system based on internal processes will aid in the reduction of implementation costs and the promotion of integration in FDI firms' overall operations.

It is important to have a commitment from the senior management of the company to guarantee that the supply chain management requirements are met. Furthermore, Carter et al (2008) stated that middle manager support is also required for successful supply chain management application adoption. According to Otto \& Kotzab (2003), it is critical to assess supply chain management performance from within the firm. Operational and managerial performance indicators are frequently used to assess supply chain management effectiveness. The study suggests the following hypothesis based on the arguments:

\section{$\mathbf{H}_{1}$ : Internal environment has a positive effect on Business Performance.}

The enterprise's external environment, which consists of two factors: consumers who use the product and suppliers, is also regarded as a critical component in the practice of supply chain management. Gurel (2015) argues that "due to customer demand for green products made from environmentally friendly materials and green production processes, businesses must integrate environmental goals into long-term strategic management”.

Consumer pressure is undoubtedly a significant role in encouraging energy companies to engage in environmentally friendly operations. With the recent rise of environmentally friendly renewable energy sources, the number of consumers has increased, necessitating more action of all kinds to ensure the environmental sustainability of all products and services supplied to customers (Kumar \& Chandrakar, 2012).

Many people have utilized cost-effective energy choices, which are frequently chosen by first-time consumers (Darby, 2006). Long-term customers, on the other hand, may choose to utilize and support a brand depending on its level of environmental commitment (Evanschitzky et al., 2006). The study presents the second and third hypotheses based on the arguments: 
H2: User pressure has a positive effect on Business Performance.

$\mathbf{H}_{3}$ : Cooperation with suppliers has a positive effect on Business Performance.

According to a series of studies, compliance with legal rules is the major driving force behind the deployment of green supply chain management (Laosirihongthong. et al., 2013). The regulatory environment is divided into three levels by Raustiala (1997): regional environmental rules, central government environmental regulations, and international environmental accords. The study presents the fourth hypothesis based on the arguments:

H4: Environmental regulations have a positive effect on Business Performance.

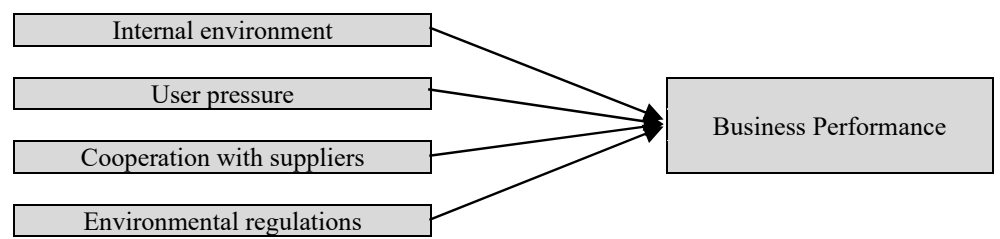

Fig 1. Model Concept

\section{Methodology}

To assess the constructs, we developed an online survey with responses graded on a five-point Likert scale $(1=$ Strongly Disagree; 5 = Strongly Agree). To statistically evaluate these results, we used the partial least squares method. After screening the data, we obtained 300 responses, with a total of 280 valid surveys. This sample size is appropriate for the model's circumstances. The sample size must fulfill the rule of thumb, which stipulates that it should be at least 10 times larger than the number of predictors (Gefen et al ,2011).

\section{Results}

Testing the reliability test construct using composite reliability (CR), average variable extracted (AVE), and alpha a (AVE) is 0.50 or more (Hair et al., 2014) shown in Table 1 .

Table 1

Test of the validity and reliability

\begin{tabular}{|c|c|c|c|c|}
\hline Code & Variable & Factor's loading & t-value & VIF \\
\hline \multicolumn{5}{|c|}{ Internal environment (Cronbach's alpha: 0.808, CR: 0.874, AVE: 0.636) } \\
\hline IE1 & Capital & 0.872 & 68.309 & 2.498 \\
\hline IE2 & Expense & 0.838 & 49.252 & 2.313 \\
\hline IE3 & Human Resources & 0.728 & 22.491 & 1.543 \\
\hline IE4 & Scale production & 0.744 & 23.550 & 1.523 \\
\hline \multicolumn{5}{|c|}{ User pressure (Cronbach's alpha: 0.809, CR: 0.874, AVE: 0.635) } \\
\hline UP1 & Information & 0.819 & 44.118 & 1.616 \\
\hline UP2 & Customer psychology & 0.788 & 31.043 & 1.740 \\
\hline UP3 & User culture & 0.814 & 42.599 & 1.760 \\
\hline UP4 & Ambient users & 0.765 & 27.031 & 1.529 \\
\hline \multicolumn{5}{|c|}{ Cooperation with suppliers (Cronbach's alpha: 0.868, CR: 0.910, AVE: 0.717) } \\
\hline CS1 & Reputation & 0.876 & 55.161 & 2.698 \\
\hline CS2 & Product price & 0.813 & 39.563 & 1.717 \\
\hline CS3 & Product quality & 0.817 & 28.171 & 1.940 \\
\hline CS4 & Long-term and sustainability & 0.878 & 59.283 & 2.592 \\
\hline \multicolumn{5}{|c|}{ Environmental regulations (Cronbach's alpha: 0.879, CR: 0.917, AVE: 0.734) } \\
\hline ER1 & Institutions & 0.825 & 42.236 & 1.933 \\
\hline ER2 & Policy & 0.858 & 46.081 & 2.403 \\
\hline ER3 & Competitor & 0.903 & 59.956 & 2.923 \\
\hline ER4 & Economy & 0.841 & 33.642 & 2.049 \\
\hline \multicolumn{5}{|c|}{ Business Performance (Cronbach's alpha: 0.868, CR: 0.910, AVE: 0.718) } \\
\hline BP1 & Company size & 0.835 & 42.271 & 2.308 \\
\hline BP2 & Liquidity & 0.911 & 78.851 & 3.308 \\
\hline BP3 & State & 0.810 & 31.772 & 1.917 \\
\hline $\mathrm{BP} 4$ & Company age & 0.830 & 38.734 & 1.994 \\
\hline
\end{tabular}

So, the overall evaluation research model can be expressed well, and we can further proceed with the analysis of hypothesis testing. 


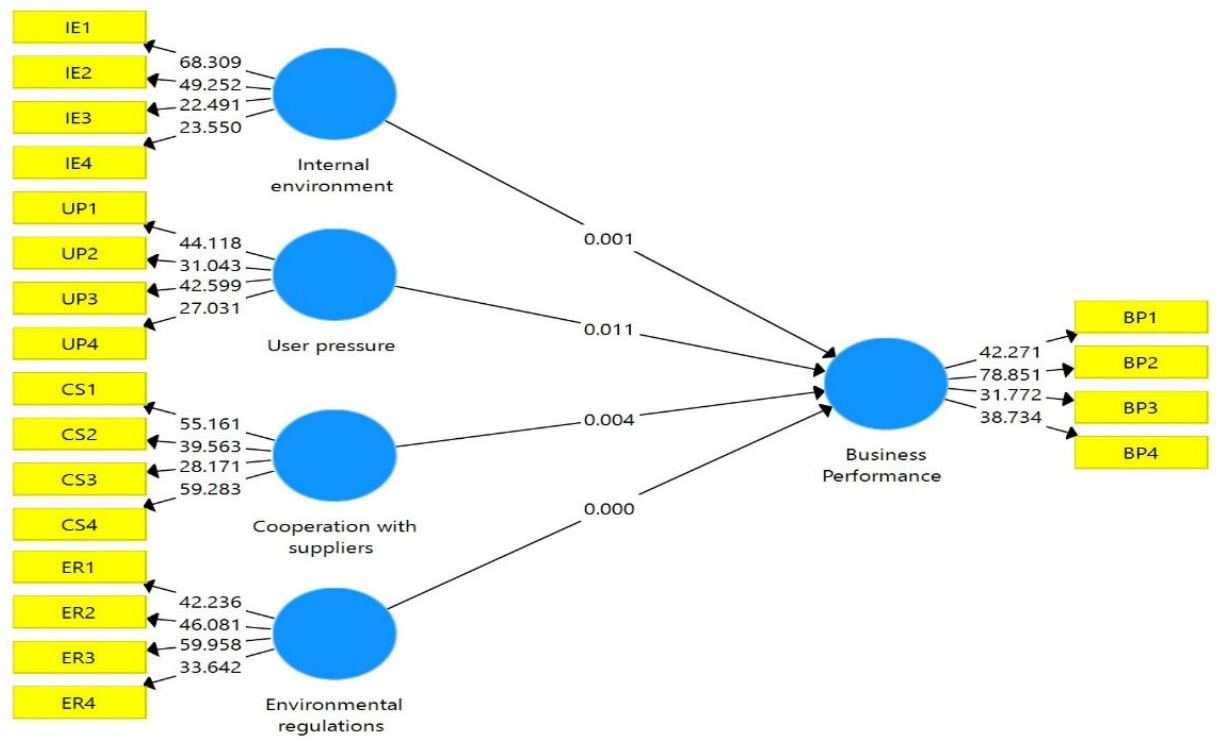

Fig. 2. Bootstrapping Result

Table 2

Test Results Path Coefficient

\begin{tabular}{llcc}
\hline & \multicolumn{1}{c}{ Hypothesis Test } & P_value & Results \\
\hline H1 & Internal environment $\rightarrow$ Business Performance. & 0.001 & Supported \\
H2 & User pressure $\rightarrow$ Business Performance. & 0.011 & Supported \\
H3 & Cooperation with suppliers $\rightarrow$ Business Performance. & 0.004 & Supported \\
H4 & Environmental regulations $\rightarrow$ Business Performance. & 0.000 & Supported \\
\hline
\end{tabular}

Based on the results of the direct relationship analysis from Table 3, it indicates that the hypothesis (H1, H2, H3 and H4 are accepted).

\section{Conclusion}

In the current era, it is critical to promote green FDI projects entering Vietnam. However, the quantity and scope of projects in the field of green energy are not commensurate with Vietnam's potential and strengths, as seen by the current scenario. Attracting green energy projects to Vietnam is critical currently, particularly as environmental degradation rises. The following measures should be adopted simultaneously to boost the operations of the foreign direct investment sector in renewable energy development in Vietnam:

Firstly, a policy to encourage and attract FDI firms into the sectors of renewable energy development is required. Furthermore, from the stage of soliciting and promoting investment, it is important to create a coordination system across ministries, branches, and municipalities to choose and propose priority investment fields and locations. Infrastructure development for underserved regions.

Secondly, it is important to continue to publish a system of legal papers in order to provide a level playing field for businesses and advantageous investment circumstances. guaranteeing reasonably synchronized and convenient inter-sectoral procedures as well as renewable energy project standards to provide a basis for funding investment projects through the one-stop-shop mechanism.

Thirdly, investigate and implement a variety of methods and regulations to promote renewable energy development, such as investment tax credits, import and export taxes, corporate income taxes, land use levy exemptions and reductions, and renewable energy project land rent. Another issue is that foreign companies cannot develop renewable energy without indigenous companies supplying the necessary equipment. As a result, major investors are still seeking strong enough partners in the nation, as well as connecting with worldwide firms to discover equipment supply sources, all of which will assist to reduce power production costs.

Fourth, a clear roadmap and more transparent renewable energy policies are required. Because they have a better knowledge of the roadmap and direction of this industry in Vietnam, several international businesses have recently invested in renewable energy. Because renewable energy is a very big capital-intensive industry, huge businesses must adhere to rigorous investment guidelines. Investors need to see the entire strategy as well as transparent policies to assure project implementation in order to attract investment. 


\section{References}

Baumgartner, R. J., \& Rauter, R. (2017). Strategic perspectives of corporate sustainability management to develop a sustainable organization. Journal of Cleaner Production, 140, 81-92.

Bhattacharya, M., Paramati, S. R., Ozturk, I., \& Bhattacharya, S. (2016). The effect of renewable energy consumption on economic growth: Evidence from top 38 countries. Applied Energy, 162, 733-741.

Carter, C., \& Rogers, D.S. (2008), A framework of sustainable supply chain management: moving toward new theory. International Journal of Physical Distribution \& Logistics Management, 38(5), 360-387.

Chavez, R., Yu, W., Feng, M., \& Wiengarten, F. (2016). The effect of customer-centric green supply chain management on operational performance and customer satisfaction. Business Strategy and the Environment, 25(3), 205-220.

Cuong, T. T., Le, H. A., Khai, N. M., Hung, P. A., Thanh, N. V., Tri, N. D., \& Huan, N. X. (2021). Renewable energy from biomass surplus resource: potential of power generation from rice straw in Vietnam. Scientific Reports, 11(1), 1-10.

Darby, S. (2006). The effectiveness of feedback on energy consumption. A Review for DEFRA of the Literature on Metering, Billing and direct Displays, 486(2006), 26.

Dai, H., Xie, X., Xie, Y., Liu, J., \& Masui, T. (2016). Green growth: The economic impacts of large-scale renewable energy development in China. Applied Energy, 162, 435-449.

Dincer, I. (2000). Renewable energy and sustainable development: a crucial review. Renewable and Sustainable Energy Reviews, 4(2), 157-175.

Evanschitzky, H., Iyer, G. R., Plassmann, H., Niessing, J., \& Meffert, H. (2006). The relative strength of affective commitment in securing loyalty in service relationships. Journal of Business Research, 59(12), 1207-1213.

Gurel, O., Acar, A. Z., Onden, I., \& Gumus, I. (2015). Determinants of the green supplier selection. Procedia-Social and Behavioral Sciences, 181, 131-139.

Hoi, H. T. (2020, October). Potential for Clean Energy Development in Vietnam. In 2020 IEEE 3rd International Conference on Renewable Energy and Power Engineering (REPE) (pp. 80-84). IEEE.

Kumar, A., Kumar, K., Kaushik, N., Sharma, S., \& Mishra, S. (2010). Renewable energy in India: current status and future potentials. Renewable and Sustainable Energy Reviews, 14(8), 2434-2442.

Kumar, R., \& Chandrakar, R. (2012). Overview of green supply chain management: operation and environmental impact at different stages of the supply chain. International Journal of Engineering and Advanced Technology, 1(3), 1-6.

Laosirihongthong, T., Adebanjo, D., \& Tan, K. C. (2013). Green supply chain management practices and performance. Industrial Management \& Data Systems, 113(8), 1088-1109.

Li, Y., Wei, L., Chi, Y., Wang, Z., \& Zhang, Z. (2016, October). Study on the key factors of regional power grid renewable energy accommodating capability. In 2016 IEEE PES Asia-Pacific Power and Energy Engineering Conference (APPEEC) (pp. 790-794). IEEE.

Otto, A., \& Kotzab, H. (2003). Does supply chain management really pay? Six perspectives to measure the performance of managing a supply chain. European Journal of Operational Research, 144(2), 306-320.

Painuly, J. P. (2001). Barriers to renewable energy penetration; a framework for analysis. Renewable Energy, 24(1), 73-89.

Tien, N. H., Phuc, N. T., Thoi, B. V., Duc, L. D. M., \& Thuc, T. D. (2020). Green economy as an opportunity for Vietnamese business in renewable energy sector. International Journal of Research in Finance and Management, 3(1), $26-32$.

Tran, H. N. (2018). Renewable Energy in Achieving Sustainable Development Goals (SDGs) and Nationally Determined Contribution (NDC) of Vietnam. Renewable Energy in Developing Countries, 41-56.

Raustiala, K. (1997). States, NGOs, and international environmental institutions. International Studies Quarterly, 41(4), 719740.

Viardot, E. (2013). The role of cooperatives in overcoming the barriers to adoption of renewable energy. Energy Policy, 63, 756-764.

Worighi, I., Maach, A., Hafid, A., Hegazy, O., \& Van Mierlo, J. (2019). Integrating renewable energy in smart grid system: Architecture, virtualization and analysis. Sustainable Energy, Grids and Networks, 18, 100226.

Zhu, Q., \& Sarkis, J. (2006), An inter-sectoral comparison of green supply chain management in China: drivers and practices, Journal of Cleaner Production, 14, 472-486. 
C 2022 by the authors; licensee Growing Science, Canada. This is an open access article distributed under the terms and conditions of the Creative Commons Attribution (CCBY) license (http://creativecommons.org/licenses/by/4.0/). 